\title{
The strange situation procedure: The role of the attachment patterns in the Italian culture
}

\section{Alessandra Simonelli ${ }^{*}$, Francesca De Palo, Marilena Moretti, Paola Merlin Baratter, Alessio Porreca}

Department of Developmental and Socialization Psychology, University of Padua, Padova Pd Italy

\section{Email address:}

alessandra.simonelli@unipd.it (A. Simonelli)

\section{To cite this article:}

Alessandra Simonelli, Francesca De Palo, Marilena Moretti, Paola Merlin Baratter, Alessio Porreca. The Strange Situation Procedure: The Role of the Attachment Patterns in the Italian Culture. American Journal of Applied Psychology. Vol. 3, No. 3, 2014 , pp. 47-56. doi: 10.11648/j.ajap.20140303.11

\begin{abstract}
The Strange Situation Procedure (SSP; Ainsworth, Blehar, Waters, Wall, 1978) is the most widely used procedure to assess attachment in early childhood (Bowlby, 1969, 1973, 1980). Indeed, this method finds very large application in many fields of research and, particularly, in the intercultural study of attachment. The intercultural applications of the SSP, are referred to various Western cultures and cultures other than the Western one, such as, for instance, the African, Chinese, Japanese and Israeli ones. In this research 76 12-month-old infants were observed in the SSP in order to assess the distribution of infant-mother attachment in the Italian culture, and to compare the pattern classification with other national (Ammaniti et al., 1994; Tambelli et al. 2008) and international non-clinical samples (van IJzendoorn et al., 1992; Schuengel et al., 1999). Results: Results show a significant lower proportion of Secure attachment and more Insecure Avoidant one in the Italian group than in US samples of meta-analytic studies. From a socio-cultural perspective, a possible explanation for the obtained results can be found in the peculiar changes which have come about in child-rearing procedures, especially in first infancy. This behavioral organization could show an adjustment strategy within a context which is not exclusively dyadic anymore, but which requires an ability to find resources even in a condition characterized by daily separations, multiple interactions and repeated caregiving micro-modifications.
\end{abstract}

Keywords: Strange Situation Procedure, Attachment Bond, Secure Attachment, Cultural Issues in Attachment

The Strange Situation is a standardized observation procedure (Ainsworth, Bell, Waters, Wall, 1978; Ainsworth, Wittig, 1969) which aims at activating and intensifying the child's attachment behavior towards his/her parent by exposing the child to a moderately, yet increasingly stressful situation (Bowlby, 1968/82, 1973, 1980). In fact, the Strange Situation takes place within a context - an observation laboratory - which is not familiar to the child: it foresees the presence of an unfamiliar adult and a series of two separations and reunions with the mother (or any other adult figure we might be interested in studying the child's attachment relationship with). This procedure is applicable to children between 12 and 24 months of age, the developmental period of attachment bond (Ainsworth, 1985; Ainsworth, Bell, Stayton, 1971). The procedure is subdivided into eight short episodes, each of them lasting approximately three minutes and following one another according to a fixed order and a clearly stated consignment (Scheme 1).

The SSP coding is based on the observation of the overall organization of a child's attachment behavior and foresees two assessment levels: the first one is based on graduated ordinal scales on a 7-point Likert scale (range 1 $-7)$, which refer to specific behavioral sequences that the child might display in the various episodes (Scheme 2). 
Scheme 1. The Strange Situation episodes (adapted from Ainsworth et al., 1978)

\begin{tabular}{|c|c|c|c|}
\hline Episode number & Participants & Length & Short description \\
\hline 1 & Mother, infant and observer & $30 \mathrm{sec}$. & $\begin{array}{l}\text { The observer introduces mother and infant into the room, then he/she leaves the } \\
\text { room }\end{array}$ \\
\hline 2 & Mother and infant & $3 \mathrm{~min}$. & $\begin{array}{l}\text { Mother does not participate while infant explores. If necessary, play activities are } \\
\text { encouraged after } 2 \text { minutes. }\end{array}$ \\
\hline 3 & Mother, infant and stranger & $3 \mathrm{~min}$. & $\begin{array}{l}\text { Stranger enters. First minute: stranger is silent. Second minute: stranger } \\
\text { converses with the mother. Third minute: stranger approaches infant. After } 3 \\
\text { minutes, mother leaves unobtrusively. }\end{array}$ \\
\hline 4 & Infant and stranger & $3 \mathrm{~min}$. or less & First separation episode. Stranger's behavior is adjusted to that of infant. \\
\hline 5 & Mother and infant & 3 min. or more & $\begin{array}{l}\text { First reunion episode. Mother greets and/or comforts infant, then tries to engage } \\
\text { him/her in play. Mother leaves again, saying "bye-bye". }\end{array}$ \\
\hline 6 & Infant alone & 3 min. or less & Second separation episode. \\
\hline 7 & Infant and stranger & $3 \mathrm{~min}$. or less & $\begin{array}{l}\text { Continuation of second separation episode. Stranger enters and adjusts behavior } \\
\text { to that of infant. }\end{array}$ \\
\hline 8 & Mother and infant & 3 min. or more & $\begin{array}{l}\text { Second reunion episode: mother greets infant, picks him/her up and comforts } \\
\text { him/her, then tries to engage him/her in play. }\end{array}$ \\
\hline
\end{tabular}

\section{Scheme 2: Assessment scales of interactive behaviors in} the Strange Situation Procedure (Ainsworth et al., 1978)

1. Proximity and contact seeking: refers to behaviors by means of which the infant seeks physical contact with his/her caregiver or else, simple proximity, as well as to the degree of intensity and persistence with which these behaviors are shown (It is applied to episodes 2, 3,5 and 8 to assess interactive behaviors towards the mother and to episodes 3, 4 and 7 to assess interactive behaviours towards the stranger).

2. Contact maintaining: refers to behaviors by means of which the infant attempts at resisting against being left and maintaining physical contact with the adult, once contact has been established (It is applied to episodes 2, 3,5 and 8 to assess interactive behaviors towards the mother and to episodes 3, 4 and 7 to assess interactive behaviors towards the stranger).

3. Resistance: refers to those opposition behaviours which show a certain degree of rage, irritation and aggressiveness. Usually, these behavioral attitudes emerge in response to the adult's attempts to get in touch or interact with the infant after the separation episodes: these attitudes can be addressed towards the adult, or else, towards the toys or any other object in the room (It is applied to episodes 2, 3, 5 and 8 to assess interactive behaviours towards the mother and to episodes 3, 4 and 7 to assess interactive behaviours towards the stranger).

4. Avoidance: refers to those behaviors which testify to the infant's attempt to ignore the adult or avoid any kind of interaction with him/her, even at a distance. When the adult tries to establish a relationship with the infant or engage him/her in play, or else, during a reunion episode, the infant walks away, turns his/her head away, looks away, turns his/her back on the adult, hides his/her face or simply carries on with his/her activities, ignoring all outside stimuli (It is applied to episodes 2, 3, 5 and 8 to assess interactive behaviors towards the mother and to episodes 3, 4 and 7 to assess interactive behaviors towards the stranger).

5. Search attitude during separation episodes: refers to those behaviors by means of which the infant looks around for his/her caregiver, when the latter is not present in the room. Some of these behaviors can be more direct and clear, such as walking towards the door, trying to open it or standing close to it most of the time. Others are weaker and less complete, such as looking at the door, walking towards the door without reaching it, looking at the chair or at mother's bag (It is applied to episodes $4,6,7$ to assess behavior towards the mother; it is not applied to the interaction with the stranger).

6. Distance interaction: refers to positive, social and communicative behaviors (smiling, vocalizing, showing or offering a toy, pointing at specific objects inside the room) which clearly show that the child wants to interact with the adult and wants to share exploration, play or his/her inner states with him/her, even though he/she does not need close physical contact (It is applied to episodes 2, 3, 5 and 8 to assess interactive behaviors towards the mother and to episodes 3, 4, 7 to assess interactive behaviors towards the stranger)

The second level is based on the observation of the way in which the behavioral systems of attachment and exploration are organized during the whole procedure both towards the caregiver, as well as the stranger, while various stress elements are introduced, one after the other and leads to the assignment of an attachment pattern according to four categories (Main, Solomon, 1986, 1990; Scheme 3): secure attachment (B) - research studies referring to "nonclinical" United States children show that between 54.9\% and $67 \%$ of the population fall into this category; avoidant attachment (A) is observed in an average range of $20.5 \%$ $22.9 \%$ of the population. Resistant attachment (C) is less frequent among the population (7.5\%-12.5\%), while disorganized/disoriented attachment (D) is observed in $14.7 \%$ of the children (van IJzendoorn, Goldberg, Kroonenberg, Frenkel, 1992). 


\section{Scheme 3: Attachment categories in infancy (Ainsworth et al., 1978; Main, Solomon, 1986, 1990)}

Secure Attachment (B) describes an infant who seeks proximity, physical contact or interaction with the caregiver. When the latter is present, the infant engages in autonomous exploration of the environment but, usually, he/she actively encourages participation of the adult. During the separation episodes, the infant clearly looks around for the adult, shows signs of stress and uneasiness which are tied to the absence of the caregiver and not to the fact that he/she has been left alone. During the reunion episodes, a secure infant displays his/her attachment towards the parent, greets him/her, seeks proximity or interaction or else, if he/she feels uneasy, he/she will seek physical contact and consolation. On the whole, when his/her caregiver returns after separation, the infant looks comforted and in fact, he/she resumes exploring the environment and the toys, displaying a typical secure base behavior.

Insecure Avoidant Attachment (A) describes an infant that clearly assumes an avoidant attitude towards his/her parent, especially during the reunion episodes. These infants appear particularly autonomous and independent, more focused on the exploration of the environment and the toys than on the presence of their caregiver. Usually, during separations, they scarcely show signs of uneasiness, they rarely look around for the adult and, during the reunion episodes, they seem to ignore or attach little importance to the fact that their caregiver is back. They tend to minimize their affective reactions, particularly after separations, and appear very busy and engaged in play. More generally, infants with insecure avoidant attachment show an unbalance between the exploration of the environment and the available toys, and attachment expressions towards their caregiver, with a preference for the first activity: with respect to their caregiver, they appear very independent, autonomous, and affectively selfsufficient. In other words, these children's distinctive feature is a tendency not to display their needs for protection, while emphasizing an autonomous and independent relational style.

Insecure Resistant/Ambivalent Attachment (C) describes infants who tend to be focused on the relationship with the adult rather than on exploration: they show little ability to explore the environment autonomously and to interact with the stranger, feel very uneasy during separation, and are difficult to comfort during reunion. In fact, even once the parent is back after separation, they do not look comforted: on the contrary, they show ambivalence on reunion and alternate and mix requests for proximity and contact with clearly resistant and extremely passive behaviors. More generally, these children display an unbalance between exploration and attachment, with a preference for the latter: the parent is not seen as a secure base, since he/she does not seem to be able to comfort the infant with his/her presence. The infant appears dependent and focused on his/her parent, with little autonomy and a tendency to show clear signs of attachment, characterized by rage or passivity, which are difficult to soothe.

Disorganized/Disoriented Attachment (D) refers to contradiction in some observed movements, which makes us think of an underlying contradiction in the infant's intentions or behavioral plans (disorganization) or else, a feeling that the little one has lost orientation in the environment which surrounds him/her (disorientation). These children's behavior is at times very confused, because they are not able to organize the situation efficiently, orientate behavior and affection, also because they assume clearly frightened and rigid attitudes both physically and through their face expressions. The most relevant aspect is that their disoriented/disorganized behavior appears only when the caregiver is present, especially during the reunion episodes.

The SPP original validation study highlights a direct correspondence between the children's scores at the scales of interactive behaviors and the assignment of a general attachment category: in other words, a discriminant analysis applied to the scores of the interactive scales leads to a distinction in 3 attachment patterns, as globally defined (Ainsworth et al., 1978). This statistical matching bears evidence of convergent validity between the two attachment classification systems within the SSP, so that the assessments obtained with the two systems do not show any significant difference. With the passing of time, this result has led to the almost exclusive use of the categorical method, which is considered more economical for the coder and, at the same time, equally reliable.

\section{Putting the Strange Situation to the Test}

Especially during the first years after its publication, the Strange Situation Procedure was used in a very comprehensive series of research studies which aimed at verifying its characteristics of validity and reliability (Solomon, George, 2002).

Regarding construct validity, the theory foresees that the quality of a child's attachment is the outcome of the type of relationship which parents and children have built during the first year of a child's life: specifically, an adult's sensitivity and responsiveness towards a child's protection needs should be associated with secure attachment (B) at 12 months, while a caregiving style which is not adequately sensitive and responsive should be at the roots of an insecure type of attachment. In this respect, the investigation was focused on maternal characteristics and offered evidence of how secure children's (B) mothers showed greater engagement in the relationship, responsiveness to their children's emotional and verbal signals (Belsky, Rovine, Taylor, 1984), adequate levels of responsiveness (Smith, Pederson, 1988), as well as higher levels of affective contact and a 
more positive affective quality (Belsky, Isabella, 1991; Isabella, 1993). Two meta-analyses on the data available in the literature (Goldsmith, Alansky, 1987; DeWolff, van IJzendoorn, 1997) show clear empirical evidence of a correlation between maternal sensitivity and attachment security, in spite of contradictory data from other research studies (Schneider-Rosen, Rothbaum, 1993; Seifer, Shiller, Sameroff, Resnik, Riordan, 1996). Finally, a series of cross-cultural research studies referring to the African, Chinese, Japanese and Israeli culture show how the association between sensitivity and attachment is broadly documented. The authors are, therefore, led to interpret these studies as further evidence for the existence of this relation, even if sensitivity does not offer a unique and comprehensive explanation of individual differences in attachment (van IJzendoorn, BakermansKranenburg, 2005; van IJzendoorn, Sagi, 2002). Subsequently, we aimed at verifying the Strange Situation's predictive validity with special reference to identifying any existing relationship between the quality of attachment - more specifically, secure attachment (B) - and the child's adjustment, since a feeling of security should work as an affective basis which favors the child's development. In this respect, reviews by Thompson (2002) and Weinfield, Sroufe, Egeland and Carlson (2002) point out how children with secure attachment at 12 months show greater social competences in the interaction with their peers and an ability to establish relationships with familiar and unfamiliar adults. Moreover, they show greater ability in affect regulation, particularly as regards negative emotions and aggressiveness; symbolic play lasts longer in these children and is more complex, and exploration sessions last longer too. Finally, these children show higher and more elaborate levels of cognitive and linguistic development (Meins, 1997; Bakermans-Kranenburg, van IJzendoorn, 1993; van IJzendoorn, Dijkstra, Bus, 1995; Weinfield, et al., 2002).

As for instrument reliability, our first aim was to verify accordance among coders: the accordance rate among expert judges tends to be very high within groups of researchers who work together, varying from the $100 \%$ accordance rate in the original study by Ainsworth et al. (1978) to $85-95 \%$ in the studies by Main and Weston (1981) and by Waters (1979), who were trained by the procedure's author herself. However, studies comparing accordance rates between judges belonging to the same group and judges of other groups also found good reliability levels for the coding procedure, varying from $80 \%$ to $88 \%$ (see Solomon, George, 2002). The test-retest reliability within a 6-month interval was quite high ranging from $50 \%$ to $92 \%$ - but not homogeneous, probably because of events and conditions which can cause variations in the attachment style developed by the child (see Solomon, George, 2002).

\section{Applications of the Strange Situation Procedure}

As already mentioned, the SSP is a very commonly used methodology, which is applied to many fields of research. We would like to mention only the intercultural study of attachment which is particularly useful for our work.

The intercultural applications of the SSP, referring to various Western cultures and cultures other than the Western one, such as, for instance, the African, Chinese, Japanese and Israeli ones (see van IJzendoorn, Sagi, 2002) were carried out with the aim of exploring to what extent each single type of attachment appears in the various cultures: particularly, these studies aimed at verifying whether secure attachment (B) is really the most adaptive and - therefore - most preferable pattern, the one which appears crosswise in the greatest number of adult-child dyads, no matter what culture they belong to. The metaanalytical work by van IJzendoorn and Kroonenberg (1988), which aimed at verifying a possible, homogeneous distribution of attachment patterns in different cultures or among different groups of individuals belonging to the same culture, highlighted the prevalence of a secure attachment pattern (B) in the "normative" samples of the majority of the studied cultures. However, the proportion of this classification varies greatly from one research to the other, even within the same culture and within groups whose socio-demographic characteristics are similar to each other. Moreover, within specific cultures, it is not possible to maintain that the secure pattern is the prevalent one in infancy: for instance, some research studies on Japanese and Israeli children show a higher proportion of ambivalent attachment (C) (Miyake, Chen, Campos, 1985; Sagi, 1990; Sagi, Lamb, Lewkowicz, Shoham, Dvir, Estes, 1985; Takahashi, 1990), whereas other research studies on German children (Grossmann, Grossmann, Huber, Wartner, 1981; Grossmann, Grossmann, Spangler, Suess, Unzner, 1985) and Italian children (Ammaniti, Candelori, Pola, Speranza, Tambelli, 1994; Fava Vizziello, Calvo, Simonelli, 2003; Tambelli, Odirisio, Speranza, Realini, Ammaniti, 2008) show a higher proportion of avoidant attachment styles (A), which the authors see as a consequence of the change in the children's caregiving practices in our country.

\section{The Research}

In the light of what has been said, and taking the start from the studies on the Strange Situation Procedure available in the literature, the present research aimed at offering an explorative study which was set out to reply and further verify some of the methodological and crosscultural aspects of this procedure. Specific goals of this research were:

(a) To investigate the distribution of attachment patterns with specific reference to a group of children belonging to the Italian culture, and to verify if secure attachment (B) actually is the prevalent and 
most frequently represented category and if its proportion is similar to the one reported by the great majority of international studies on groups of children who were born at term and do not belong to underprivileged social classes (van IJzendoorn, Sagi, 2002). As previously noticed, the debate on the intercultural universality of a secure attachment pattern is still very heated and far from an exhaustive "resolution". The aim of the present study was to better understand the intercultural aspects of attachment, with specific reference to the Italian culture and its possible peculiar characteristics, which form the basis of caregiving practices and, therefore, the development of a specific attachment model;

(b) Within the categories of insecure attachment, to look for any prevalent model which might characterize some specific aspects of the Italian culture, as already indicated by previous, national research studies (Ammaniti et al., 1994; Fava Vizziello et al., 2003), which highlighted a prevalence of children with avoidant attachment pattern (A). This was interpreted as a form of adjustment to the current caregiving and growth conditions in infancy, also tied to the changes and characteristics of the new families. However, these data do not go in a unique direction: a recent work by Tambelli et al. (2008) did not seem to confirm a prevalence of the Avoidant style in groups of children belonging to our culture. On the contrary, its findings testified a distribution which is similar to the expected, theoretical one, according to which secure attachment is the most widespread - and therefore most numerous relational-interactive style within non-clinical groups. Even in this sense, the present study tried to contribute to a clarification of some critical aspects in the attachment evaluation.

\subsection{Participants}

The research was carried out on a group of 76 motherchild dyads. The recruited mothers belonged to a more comprehensive research project on parenthood transition. Therefore, we can say that this was a self-selected group.

At the time of administration, children - 33 baby girls (43.3\%) e 43 baby boys (56.6\%) - were between 11 and 14 months of age (mean age $=12$ months and 24 days, $\mathrm{SD}=19.55$ days). The mothers' age ranged from 26 to 42 years (mean age $=33$ years, $\mathrm{SD}=3.76$ ), while the fathers' age ranged from 28 to 42 years (mean age $=33.01$ years, $\mathrm{SD}=4.44$ ). As for their educational level, $58.3 \%$ of the mothers had a University degree, $40.3 \%$ had a high school degree, the remaining $1.4 \%$ had completed the first level of secondary school. Concerning their profession, $48 \%$ of our subjects were employees, $13.3 \%$ worked as professionals, while the remaining $38.7 \%$ either did not work, or else were employed on a part-time basis.

\subsection{Data Collection and Coding}

Data collection took place in the laboratories of the Department of Developmental and Socialization Psychology at the University of Padua, where dyads were administered the Strange Situation Procedure (SSP, Ainsworth, Wittig, 1969; Ainsworth et al., 1978): all procedures were videotaped and coded by 6 independent judges who had received appropriate training ${ }^{1}$. After having completed their training, the 6 judges were randomly split in pairs: 2 pairs coded 50 SSP each, whereas 1 pair coded 52 procedures. Videos were subdivided into 3 groups: group 1 and 2 (25 SSP), group 3 (26 SSP). Each pair of judges was given a set number of procedures to code, according to the following scheme: the first pair of judges coded the SSP group 1 according to the pattern method, whereas they were asked to codify the SSP group 2 according to the system of interactive behaviors; the second pair of judges coded the SSP group 2 according to the pattern method and the SSP group 3 according to the system of interactive behaviors; the third pair of judges coded the SSP group 3 according to the pattern method and the SSP group 1 according to the system of interactive behaviors. In this way, no video clip was coded by the same pair of judges by applying the two (different) methods at the same time, so as to prevent any possible bias or mistake during the coding procedure.

Each video clip was classified according to one of the four attachment categories (see Scheme 3): secure (B), avoidant (A), resistant (C), disorganized/disoriented (D). Judges reached a mean concordance of $80 \%(\mathrm{~K}=.74)$. At the same time, all SSPs were coded by means of the six scales of interactive behaviors (Ainsworth et al., 1978): while the original coding required assessment of the six interactive variables every 15 seconds, in the present research assessment refers to each single episode (3 minutes). Each scale was applied to episodes 2, 3, 5 and 8 to assess the child's interactive behaviors towards the mother, whereas each scale was applied to episodes 3, 4 and 7 to assess the child's interactive behaviors towards the stranger (see scheme 1). Through these scales, each procedure episode is assigned a score on a 7-point Likert scale (range $1-7$ ). The scores assigned to each single episode are then summed up, so as to obtain a global score for each scale. In brief, the scales referring to the child's

\footnotetext{
${ }^{1}$ Seven independent judges were appointed for the research. One of them (a trained judge) had been trained to code the Strange Situation by Prof. Sroufe at the Child Development Institute of Minneapolis, University of Minnesota, whereas a second one (an expert judge) was an expert in assessing attachment and had completed a coding training with Prof. Crittenden (Department of Developmental and Socialization Psychology, University of Padua). The remaining 5 judges were formed and trained by the first two ones: more specifically, judges in training coded 30 videos and tested the reliability of their coding with the expert judge. Since the obtained concordance index reached a value of $\mathrm{ICC}=.945$, the 5 judges in training were reputed to be able to proceed with data coding, while the expert judge was asked for advice for difficult SSP coding cases only. In brief, the coding procedure was carried out by 6 judges: 5 judges in training and 1 trained judge.
} 
interactive behaviors towards the mother will feature a global score varying from 4 to 28 points (each scale score ranging from 1 to 7,4 single episode scores having to be summed up), whereas scales referring to the child's interactive behaviors towards the stranger will feature a global score varying from 3 to 21 points (each scale score ranging from 1 to 7,3 single episode scores having to be summed up). Concordance calculated with the Interclass Correlation Coefficient (ICC) reached .988.

\section{Results}

The first goal of our research was to supply further data on the distribution of attachment patterns in infancy, with specific reference to a group of children belonging to the Italian culture. In fact, we wanted to test if secure attachment (B) actually was the prevalent and most frequently represented category in our culture too. Tables 1 and 2 show the distribution of attachment patterns referring to 3 and 4 attachment categories.

Table 1. Comparison between the sample of our research (Padova, 2010) and other Italian sample groups (Tambelli et al., 2008; Fava Vizziello et al., 2003; Ammaniti et al., 1994), with 3 and 4 attachment categories (frequencies, percentages and corrected standard residuals).

\begin{tabular}{|c|c|c|c|c|c|c|c|c|c|}
\hline \multirow[b]{2}{*}{3 categories } & \multicolumn{5}{|c|}{ Attachment distribution } & \multicolumn{4}{|c|}{ Corrected standard residuals } \\
\hline & $\mathrm{A}$ & $\mathrm{B}$ & $\mathrm{C}$ & $\mathrm{D}$ & $\mathrm{N}$ & A & $\mathrm{B}$ & $\mathrm{C}$ & $\mathrm{D}$ \\
\hline Padova & 27 & 38 & 11 & 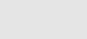 & 76 & -1.1 & 4 & 12 & \\
\hline 2010 & $35.5 \%$ & $50 \%$ & $14.5 \%$ & & $100 \%$ & & .4 & 1.2 & \\
\hline Fava Vizziello et al. & 17 & 19 & 7 & 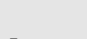 & 43 & 0 & & & \\
\hline 2003 & $17.3 \%$ & $20.9 \%$ & $4.9 \%$ & - & $100 \%$ & .0 & -.7 & 1.2 & \\
\hline Ammaniti et al. 1994 & $\begin{array}{l}23 \\
47.9 \%\end{array}$ & $\begin{array}{l}24 \\
50 \%\end{array}$ & $\begin{array}{l}1 \\
2.1 \%\end{array}$ & - & $\begin{array}{l}48 \\
100 \%\end{array}$ & 1.3 & .2 & -2.4 & \\
\hline 4 categories & A & B & $\mathrm{C}$ & $\mathrm{D}$ & $\mathrm{N}$ & A & $\mathrm{B}$ & $\mathrm{C}$ & $\mathrm{D}$ \\
\hline Padova & 23 & 38 & 9 & 9 & 76 & & & & \\
\hline 2010 & $30.3 \%$ & $50 \%$ & $11.8 \%$ & $7.9 \%$ & $100 \%$ & 1.2 & -.6 & 1.9 & -2.1 \\
\hline $\begin{array}{l}\text { Tambelli et al. } \\
2008\end{array}$ & $\begin{array}{l}3 \\
7.5 \%\end{array}$ & $\begin{array}{l}35 \\
87.5 \%\end{array}$ & 0 & $\begin{array}{l}2 \\
5 \%\end{array}$ & $\begin{array}{l}40 \\
100 \%\end{array}$ & $-2.9 *$ & $4.9^{*}$ & -2.0 & -1.9 \\
\hline $\begin{array}{l}\text { Fava Vizziello et al. } \\
2003\end{array}$ & $\begin{array}{l}10 \\
23.3 \%\end{array}$ & $\begin{array}{l}18 \\
41.9 \%\end{array}$ & $\begin{array}{l}6 \\
14 \%\end{array}$ & $\begin{array}{l}9 \\
20.9 \%\end{array}$ & $\begin{array}{l}43 \\
100 \%\end{array}$ & -.4 & -1.6 & 1.9 & 1.3 \\
\hline Ammaniti et al. 1994 & $\begin{array}{l}17 \\
35.4 \%\end{array}$ & $\begin{array}{l}18 \\
37.5 \%\end{array}$ & - & $\begin{array}{l}13 \\
27.1 \%\end{array}$ & $\begin{array}{l}48 \\
100 \%\end{array}$ & 1.8 & -2.4 & -2.2 & $2.8^{*}$ \\
\hline
\end{tabular}

* Significant corrected standard residuals $(z$ critical $=2.49$ with 3 categories; $z$ critical $=2.77$ with 4 categories $)$.

Table 2. Comparison between the sample of our research (Padova 2010) and other international sample groups (Ainsworth et al., 1978; Van Ijzendoorn et al., 1992; 1999) with 3 and 4 attachment categories (frequencies, percentages and corrected standard residuals).

\begin{tabular}{|c|c|c|c|c|c|c|c|c|c|}
\hline \multirow[b]{2}{*}{3 categories } & \multicolumn{4}{|c|}{ Attachment distribution } & & \multicolumn{4}{|c|}{ Corrected standard residuals } \\
\hline & A & $\mathrm{B}$ & $\mathrm{C}$ & $\mathrm{D}$ & $\mathrm{N}$ & A & $\mathrm{B}$ & $\mathrm{C}$ & $\mathrm{D}$ \\
\hline Italy & 67 & 81 & 19 & - & 167 & & & & \\
\hline $\begin{array}{l}\text { 2010-2003-1994 } \\
\text { (3 sample groups) }\end{array}$ & $37 \%$ & $48 \%$ & $15 \%$ & & $100 \%$ & & & & \\
\hline Ainsworth et al. & 22 & 70 & 13 & - & 105 & $-3.3 *$ & $2.9^{*}$ & .3 & \\
\hline 1978 & $20.9 \%$ & $66.7 \%$ & $12.4 \%$ & & $100 \%$ & & & & \\
\hline van IJzendoorn et al. , 1992 & 325 & 1062 & 197 & - & 1584 & $-5.8 *$ & $4.8^{*}$ & .4 & \\
\hline (21 sample groups) & $20.5 \%$ & $67 \%$ & $12.5 \%$ & & $100 \%$ & & & & \\
\hline 4 categories & A & B & $\mathrm{C}$ & $\mathrm{D}$ & $\mathrm{N}$ & A & B & $\mathrm{C}$ & $\mathrm{D}$ \\
\hline Padova & 33 & 56 & 15 & 15 & 119 & $3.8^{*}$ & $-3.2 *$ & 1.5 & -.7 \\
\hline $2010-2003$ & $27.7 \%$ & $47.1 \%$ & $12.6 \%$ & $12.6 \%$ & $100 \%$ & & & & \\
\hline Schuengel et al., 1999 & 311 & 1299 & 182 & 312 & 2104 & $-3.8 *$ & $3.2 *$ & -1.5 & .7 \\
\hline (15 samples) & $14.8 \%$ & $61.7 \%$ & $8.7 \%$ & $14.8 \%$ & $100 \%$ & & & & \\
\hline
\end{tabular}

* Significant corrected standard residuals $(z$ critical $=2.24$ with 3 categories; $z$ critical $=2.39$ with 4 categories $)$.

In order to test the reliability of our coding procedures with three and four attachment categories, the obtained distribution data were compared both with data referring to Italian children, as well with international data derived from meta-analyses available in the literature, by the application of Chi-Square statistic. The intra-cultural comparison between results obtained through the present study and data derived from works by Ammaniti, Candelori, Pola, Speranza and Tambelli (1994), and Fava Vizziello, Calvo, Simonelli (2003) - both referring to groups of Italian children - highlighted a substantially homogeneous distribution, when three attachment categories are taken into account $\left[\chi^{2}(\mathrm{~N}=167,4)=6.54\right.$, $\mathrm{p}=.162$, ns. $]$. However, if we include a $4^{\text {th }}$ category, that is, disorganized-disoriented attachment, we do find distribution differences $\left[\chi^{2}(\mathrm{~N}=207,9)=42.54, \mathrm{p}=.000\right]$. Data as they appear in the total distribution can be better explained if we observe what is put into evidence by the analysis of the Corrected Standard Residuals (Table 1): in fact, differences between groups seem to be brought about by a different proportion of avoidant and secure attachment patterns in the work by Tambelli et al. (2008) 
when compared with other Italian groups (Padova 2010; Fava Vizziello et al. 2003; Ammaniti et al., 1994), when taking 3 attachment patterns into consideration. As for the disorganized/disoriented (D) pattern, differences seem to be brought about by a higher proportion of children who are assigned to this category within the group studied by Ammaniti et al. (1994). To sum up, no intra-cultural differences are evidenced in the attachment pattern distribution if we take a 3-category distribution into consideration: on the contrary, significant differences emerge if we assess distributions with 4 categories. This result introduces the need for a statistical test - at intercultural level - of the homogeneity between our results and the ones published in the international literature. In order to do so, since there was no significant pattern distribution difference between the Italian groups which had been assessed on the basis of 3 categories, we started from the assumption that those distributions were homogeneous, and we united them in one single sample group.

First of all, we compared the Italian data with those reported by Ainsworth et al. (1978) as well as with those by van IJzendoorn, Goldberg, Kroonenberg and Frenkel (1992): in fact, these data are prototypical for the American, 3-category distributions. On the whole, distributions proved to be significantly different [compared to Ainsworth et al. (1978): $\chi^{2}=(\mathrm{N}=272,2)=$ $11.12, \mathrm{p}=.004$; compared to van IJzendoorn et al. (1992): $\left.\chi^{2}=(\mathrm{N}=1751,2)=34.02, \mathrm{p}=.000\right]$. Moreover, the Corrected Standard Residuals indicate that in both cases, the difference within the Italian sample group is brought about by a less significant presence of children with a secure attachment pattern and a bigger presence of children with an avoidant attachment pattern (Table 2).

A similar comparison was carried out on a series of 15 sample groups of children belonging to the general American population (Schuengel, van IJzendoorn, Bakermans-Kranenburg, 1999), while taking into consideration a 4-category attachment distribution. This comparison highlighted significant differences between the two samples $\left[\chi^{2}(\mathrm{~N}=2223,3)=18.55, \mathrm{p}=.000\right]$. This result somehow replicates the result which was obtained when considering a 3-category distribution: in fact, the Corrected Standard Residuals indicate that the difference is once again brought about by a lower number of children with a secure attachment pattern $(\mathrm{z}=-3.2, \mathrm{z}$ critical $=2.39$ ) and a bigger number of children with an avoidant attachment pattern $(\mathrm{z}=3.8, \mathrm{z}$ critical $=2.39$; Table 2).

These data also serve our second purpose, that is, our wish to test whether we can talk of prevalent insecure attachment models which are typical of the Italian culture: similarly to what had been evidenced by previous research studies, they highlight a prevalence of the avoidant pattern to the detriment of the secure pattern, which is present in non-clinical groups belonging to the Italian population (Ammaniti et al., 1994; Fava Vizziello et al., 2003).

\section{Discussion and Conclusions}

The first goal of our work was to study any possible specific trend in attachment distribution within the studied group and, more generally, within the Italian children population during the first year of life. In theory, from an evolutionary point of view, a secure attachment style is considered a preferable strategy, which should characterize the majority of normal, middle class, healthy children who are raised in stable conditions, regardless of the cultural niche they were born and grow up in (Ainsworth et al., 1978). Actually, the obtained results seem to lead, at least partially, towards a different direction. In fact, the studied group shows a significantly lower secure attachment proportion both if compared with the proportion highlighted in the historical study by Ainsworth et al. (1978), as well as with the one emerging from the metaanalytical studies carried out by van IJzendoorn et al. (1992) and by Schuengel et al. (1999) on numerous samples belonging to the US culture. Since these samples are very big, they are considered to be representative of the population they belong to. This datum comes to the forefront even though the secure attachment proportion refers to $50 \%$ of the group, that is, a fairly high share of subjects. However, it does not reflect the expected prevalence of a secure attachment with respect to the other patterns. Similarly, the Italian children group shows a higher proportion of avoidant attachment, which differentiates it from comparison groups.

This peculiarity had already been highlighted in a previous paper by one of us (Fava Vizziello et al., 2003) and, at international level, in a study by Grossmann et al. (1981), where the proportion of subjects featuring an avoidant attachment even outnumbered the proportion of secure children (24 avoidant subjects, that is, $52.1 \%$, and 16 secure subjects, that is, $34.7 \%$ ). This results places a distinction between that sample and samples belonging to the American culture, with reference to both attachment pattern proportions (van IJzendoorn, Kroonenberg, 1988), even though the European population samples' distribution is substantially homogeneous when compared with the American population included in the meta-analysis.

A possible explanation for the peculiarity of these attachment patterns - if we consider three categories - can be found in the intra-cultural comparisons which were carried out and which highlighted a substantially homogeneous distribution both with reference to secure attachment, as well as to the avoidant one. As a matter of fact, the research studies that were used for the above mentioned comparison included families and children coming from different regions and with partially different cultural traditions and models, although they all belonged to the Italian macro-culture. Moreover, the team of researchers received their training for administering the instrument and coding the procedure at different times and in different ways: therefore, we can consider them to be independent. The characteristics of the subjects and 
research studies that were taken into consideration seem to testify that the obtained distribution can be considered typical of children belonging to the Italian culture, and not just the result of peculiarities that might only be typical of the very samples or the research design: this element further supports the representative value of our group of subjects with reference to the general Italian population. As a matter of fact, these data lead us to affirm that some of the Italian children's peculiar attachment behaviors during the Strange Situation originate from the mostly homogeneous rearing context they belong to.

In general, we can say that the Italian children's distinctive feature is a sort of shift of their attachment strategies towards insecurity: more specifically, a shift towards avoidant behavior models and a greater degree of independence with reference to their attachment figures.

From a socio-cultural perspective, a possible explanation for the obtained results can be found in the peculiar changes which have come about in child-rearing procedures, especially in first infancy. As for the influence of cultural and individual expectancies in modifying and adjusting the needs and the biological basis of attachment behaviors: in accordance with what has been stated by Ammaniti et al. (1994), the obtained results could also be interpreted in relation to the current children's exposure to various daily separations from their maternal figures. During these separations, children have to confront themselves with alternative caregiving figures (grandparents, baby day care centres, nursery schools, baby-sitters, etc.): not only does this condition imply a change in the number of people at the child's disposal, but it also brings about a lack of continuity in the supplied caregiving practices. In this sense, this discontinuity could derive from the child's more and more complex relational world, which implies the need to acquire an ability to come to terms with the repeated separations from the mother, all this by means of mainly avoidant measures. The main point is trying to understand whether this behavioral organization is really tied to less maternal responsiveness and a tendency to refuse physical contact - as was observed in the mothers of avoidant American and German children (Ainsworth et al., 1978; Grossmann et al., 1981) - or else, if it is an adjustment strategy within a context which is not exclusively dyadic anymore, but which requires an ability to find resources even in a condition characterized by daily separations, multiple interactions and repeated caregiving micro-modifications. The avoidance strategies put into effect by children in the present research can, therefore, be considered as forms of relational organization, whose function is to help the child to adjust to a caregiving context where a greater self-control ability and lower stress levels at separation are the best possible response, while not preventing mother and child from building a relationship which is functional to the development of the little one.

Finally, the results of our research seem to point out some peculiarities of the Italian cultural context with regard to developing attachment: there seems to be a lower degree of security as a distinctive feature of the motherchild relationship. Consequently, further research studies are needed, first of all, in terms of longitudinal research designs, in order to offer further indication on the evolution of attachment quality over time within the mother-child dyad. Secondly, greater emphasis should be placed upon the assessment of contextual factors intervening in the attachment formation process: they can have a direct, or else an indirect impact on the child. Among the first ones, we enumerate mother sensitivity and other parents' or child's characteristics (such as temperament), whereas the second ones (which influence the caregiver) include pair relationship quality, family style, perceived social support, the role of other caregiving figures who look after the child when parents are absent (such as, for instance, grandparents or child care providers).

\section{References}

[1] Ainsworth, M. D. S. (1985). Patterns of infant-mother attachment: antecedents and effects on development. Bulletin of the New York Academy of Medicine, 61, 771-791

[2] Ainsworth, M. D. S., Bell, S. M., Stayton, D. J. (1971). Infant-mother attachment and social development: socialization as a product of reciprocal responsiveness to signals. In M. P. M. Richards (Eds), The integration of a child into a social world, Cambridge University Press, London, 99-135

[3] Ainsworth, M. D., Blehar, M., Waters, E., Wall, S. (1978). Patterns of attachment. Hillsdale, NJ: Erlbaum

[4] Ainsworth, M. D. S, Wittig B. A. (1969). Attachment and exploratory behavior of one-year-olds in a strange-situation. In B. M. Foss (Eds), Determinants of infant behavior IV, Methuen, London, 113-136.

[5] Ammaniti M., Candelori C., Pola M., Speranza A. M., Tambelli R. (1994). Influenze culturali e dinamiche relazionali nell'attaccamento infantile: Indagine su un campione italiano, Età Evolutiva, 47, 90-109

[6] Bakermans-Kranenburg M. J., van Ijzendoorn M H. (1993). A psychometric study of the Adult Attachment Interviewreliability and discriminant validity. Developmental Psychology, 29, 870-879

[7] Belsky, J., Rovine, M., Taylor, D. G. (1984). The Pennsylvania Infant and Family Development Project, III. The origins of individual differences in infant-mother attachment: Maternal and infant contributions. Child Development, 55, 718-728

[8] Belsky J., Isabella R. A. (1991). Interactional synchrony and the origins of infant-mother attachment: a replication study. Child Development , 62, 373-384

[9] Bowlby J. (1968/1982). Attachment and loss: Vol. 1. Attachment. Basic Books, (NY)

[10] Bowlby J. (1973). Attachment and loss, Vol. 2, Separation, anxiety and anger, Hogarth Press, London. 
[11] Bowlby J. (1980). Attachment and loss, vol. 3, Loss, sadness and depression, Hogarth Press, London.

[12] De Wolff M. S., Ijzendoorn M. H. Van (1997). Sensitivity and attachment: a meta-analysis on parental antecedents of infants attachment, Child Development, 68, 571-591

[13] Fava Vizziello G., Calvo V., Simonelli A. (2003). Sicurezza e insicurezza dell'attaccamento nella prima infanzia in una prospettiva interculturale, Età Evolutiva, 75, 36-50

[14] Goldsmith H. H., Alansky J. A. (1987). Maternal and infant predictors of attachment: A meta-analytic review, Journal of Clinical and Consulting Psychology, 55, 805-816

[15] Grossmann K. E., Grossmann K., Huber F., Wartner U. (1981). German children's behavior towards their mothers at 12 months and their fathers at 18 months in Ainsworth's Strange Situation, International Journal of Behavioral Development, 4, 157-181

[16] Grossmann K. E., Grossmann K., Spangler G., Suess G., Unzner L. (1985). Maternal Sensitivity and Newborns' Orientation Responses as Related to Quality of Attachment in Northern Germany. In I. Bretherton, E. Waters (Eds.), Growing Points of Attachment Theory and Research, in "Monograph of the Society for Research in Child Development", 50, 1-2, 209, 233-56

[17] Isabella R. A. (1993). Origins of attachment: maternal interactive behavior across the first year. Child Development, $64,605-621$

[18] Main M., Solomon J. (1986). Discovery of a new, insecuredisorganized-disoriented attachment pattern. In: Brazelton T.B., Yogman M. (Eds) Affective development in infancy, Ablex, Norwood

[19] Main M., Solomon J. (1990). Procedures for identifying infants ad disorganized-disoriented during Ainsworth Strange Situation. In: Greenberg M. T., Cicchetti A., Cummings M. E. (Eds) Attachment in the preschool years. Theory, research and intervention, The University of Chicago Press, Chicago

[20] Main, M., Weston, D. (1981). Quality of attachment to mother and to father: related to conflict behaviour and the readiness for establishing new relationships, Child Development, 52, 932-940

[21] Meins E. (1997). Security of Attachment and the Social Development of Intelligence, Psychology Press, Hove

[22] Miyake K., Chen S., Campos J. J. (1985). Infant temperament, Mother's Mode of Interaction, and Attachment in Japan: An Interim Report. In I. Bretherton, E. Waters (Eds), Growing Points of Attachment Theory and Research, in Monographs of the Society for Research in Child Development, 50, 1-2, 209, 276-97

[23] Sagi A. (1990). Attachment theory and research from a cross-cultural perspective. Human Development, 33, 10-22

[24] Sagi A., Lamb M. E., Lewkowicz K. S., Shoham R., Dvir R., Estes D., (1985). Security of infant-mother-father, and metapelet attachment among kibbutz-reared Israeli children. In I. Bretherton, E. Waters (Eds), Growing points in attachment theory and research, Monographs of the Society for Research in Child Development, 50, 1-2, 209, 257-275
[25] Schuengel C., Bakermans-Kranenburg M. J., Ijzendoorn M. H. Van (1999). Frightening maternal behavior linking unresolved loss and disorganized infant attachment. Journal of Consulting and Clinical Psychology, 67, 54-63.

[26] Schneider-Rosen K., Rothbaum P. (1993). Quality of Parental Caregiving and Security of Attachment, Developmental Psychology, 29, 358 - 367

[27] Seifer R., Shiller M., Sameroff A. J., Resnik S., Riordan K., (1996). Attachment, maternal sensitivity and infant temperament during the first year of life, Developmental Psychology, 32, 1, 12-25

[28] Smith, P. B., Pederson, D. R. (1988). Maternal sensitivity and patterns of infant-mother attachment. Child Development, 59, 4, 1097-1101

[29] Solomon J., George C. (2002). Attaccamento e accudimento: il sistema comportamentale di accudimento. In J. Cassidy, P. R. Shaver (Eds.), Manuale dell'attaccamento. Roma, Fioriti Editore, $737-760$

[30] Takahashi K., (1990). Are the key assumptions the "Strange Situation" procedure universal? A view from Japanese research, Human Development, 33, 23-30

[31] Tambelli R., Odorisio F, Speranza A. M., Realini R, Ammaniti M. (2008). Le Differenze di gioco tra madrebambino e padre-bambino: uno studio osservativo sull'attività ludica durante la Strange Situation. Psicologia Clinica Dello Sviluppo, 2, 200-216

[32] Thompson R. A. (2002). Attaccamento infantile e sviluppo successivo. In J. Cassidy, P. R. Shaver (Eds), Manuale dell'attaccamento, Fioriti Editore, Roma, 807-830

[33] van Ijzendoorn M. H., Kroonenberg P. M (1988). Crosscultural patterns of attachment: a meta-analysis of the strange situation. Child Development, 59, 147-156

[34] van Ijzendoorn M. H., Bakermans-Kranenburg M. (2005). Sensibilità materna e temperamento infantile nella formazione del legame di attaccamento. In Cassibba R., van IJzendoorn M. H. (Eds), L'intervento basato sull'attaccamento, Bologna: Il Mulino

[35] van Ijzendoorn M. H., Dijkstra J., Bus A. G. (1995). Attachment, intelligence and language: a meta-analysis, Social Development, 4, 115-128

[36] van Ijzendoorn M. H., Goldberg S., Kroonenberg P. M., Frenkel O. J. (1992). The relative effects of maternal and child problems on the quality of attachment: a meta-analysis of attachment in clinical samples, Child Development , 63, $840-858$

[37] van Ijzendoorn M. H., Kroonenberg P. M. (1988). Crosscultural patterns of attachment: a meta-analysis of the strange situation. Child Development, 59, 147-156.

[38] van Ijzendoorn M. H., Sagi A. (2002). Modelli transculturali di attaccamento: dimensioni universali e contestuali. In Cassidy J., Shaver P. R., Manuale dell'attaccamento, Fioriti Editore, Roma, 807-830

[39] Waters E. (1979). The reliability and Stability of Individual Differences in Infant-Mother Attachment, Child Development, 49, 971-5 
[40] Weinfield N. S., Sroufe A., Egeland B., Carlson E. A. (2002). La natura delle differenze individuali nell'attaccamento del bambino al caregiver. In J. Cassidy, P.
R. Shaver, Manuale dell'attaccamento, Fioriti Editore, Roma, 78-100 